\title{
Effectiveness of Omalizumab in Severe Allergic Asthma and Nasal Polyposis: A Real-Life Study
}

\author{
Tiotiu $\mathrm{A}^{1,2}$, Oster $\mathrm{JP}^{3}$, Roux $\mathrm{PR}^{4}$, Nguyen Thi $\mathrm{PL}^{5}$, Peiffer $\mathrm{G}^{6}$, Bonniaud $\mathrm{P}^{7-9}$, Dalphin $\mathrm{JC}^{4,10}$, de Blay F $\mathrm{F}^{11,12}$ \\ 'Department of Pulmonology, University Hospital of Nancy, Nancy, France \\ 2EA 3450 DevAH - Development, Adaptation and Disadvantage, Cardiorespiratory Regulations and Motor Control, University of Lorraine, Nancy, France \\ ${ }^{3}$ Department of Pulmonology, Hospital of Colmar, Colmar, France \\ ${ }^{4}$ Department of Pulmonology, University Hospital of Besançon, Besançon, France \\ ${ }^{5}$ Centre hospitalier universitaire de Nancy, Plateforme d'aide à la recherche clinique, Nancy, France \\ ${ }^{6}$ Department of Pulmonology, Hospital of Metz-Thionville, Thionville, France \\ ${ }^{7}$ Department of Pulmonary Medicine and Intensive Care Unit, University Hospital, Dijon, France \\ ${ }^{8}$ Inserm, LNC UMR866, LipSTIC LabEx team, Dijon, France \\ ${ }^{9}$ Bourgogne Franche-Comté University, Dijon, France \\ ${ }^{10}$ Franche-Comté University, Besançon, France \\ ${ }^{11}$ Department of Pulmonology-Allergology, University Hospital of Strasbourg, Strasbourg, France \\ ${ }^{12}$ University of Strasbourg, Strasbourg, France
}

J Investig Allergol Clin Immunol 2020; Vol. 30(1): 49-57

doi: 10.18176/jiaci.0391

\begin{abstract}
Background: Omalizumab is a human anti-IgE antibody approved for the treatment of severe allergic asthma (SAA). However, its effectiveness in SAA associated with chronic rhinosinusitis with nasal polyposis (CRSNP+) is less well documented.

Objective: The aim of this study was to evaluate the real-life effectiveness of omalizumab in patients with SAA and CRSNP+ who tolerated and did not tolerate aspirin.

Methods: We performed a retrospective, observational, multicenter, real-life study of patients with SAA and CRSNP+ treated with omalizumab for 6 months. Asthma outcome parameters (symptoms, number of salbutamol rescues/wk, number of moderate/severe exacerbations, Asthma Control Test score, and lung function), sinonasal outcome parameters (symptoms, number of episodes of acute rhinosinusitis, sinus computed tomography images, nasal polyps endoscopy score), and serum eosinophil levels were analyzed 6 months before and after treatment with omalizumab.

Results: Twenty-four adult patients were included (9 with documented aspirin intolerance). All respiratory parameters were significantly improved by the treatment. In parallel, a significant improvement was observed in sinonasal clinical outcomes and sinus computed tomography images, with no major effect on the nasal polyps endoscopy score. The serum eosinophil count decreased significantly after 6 months of treatment with omalizumab.

Conclusion: Treatment of SAA with omalizumab improves the outcome of associated CRSNP+, thus supporting the concept of a "one airway disease".
\end{abstract}

Key words: Severe allergic asthma. CRSNP+. Effectiveness of omalizumab.

\section{Resumen}

Antecedentes: El omalizumab es un anticuerpo anti-IgE humanizado aprobado para el tratamiento del asma alérgica grave (SAA), si bien su eficacia, cuando ésta se asocia a la rinosinusitis crónica con poliposis nasal (CRSNP+), está menos documentada.

Objetivo: El objetivo de este estudio fue evaluar en "vida real" la eficacia de omalizumab en pacientes con SAA y CRSNP+ con o sin intolerancia a la Aspirina.

Métodos: Se realizó un estudio retrospectivo, observacional y multicéntrico, en vida real que incluyó pacientes con SAA y CRSNP+ que fueron tratados con omalizumab durante 6 meses. Las variables de eficacia en relación al asma (síntomas, número de inhalaciones de rescate de salbutamol por semana, número de exacerbaciones moderadas/graves, puntuación de la prueba de control del asma (ACT) y función pulmonar), y de la rinosinusitis (síntomas, número de rinosinusitis aguda, puntuación en tomografía computarizada, puntuación del tamaño de los pólipos en la endoscopia nasal) y el nivel de eosinófilos en sangre se analizaron antes y después de 6 meses de tratamiento con omalizumab. Resultados: Se incluyeron veinticuatro pacientes adultos (nueve con una intolerancia a la Aspirina documentada). Todas las variables de eficacia en relación al asma mejoraron significativamente con el tratamiento. Paralelamente, las variables clínicas de eficacia en rinosinusitis y la puntuación de las imágenes tomográficas de los senos paranasales mejoraron significativamente, si bien no se observó un efecto relevante en la puntuación de los pólipos en la endoscopia nasal. El nivel de eosinófilos en sangre disminuyó significativamente después de 6 meses de tratamiento con omalizumab.

Conclusión: El tratamiento con omalizumab en pacientes con SAA induce paralelamente una mejoría clínica y radiológica de la CRSNP+ asociada, lo que apoya el concepto de una única enfermedad de las vías respiratorias.

Palabras clave: Asma alérgica grave. CRSNP+. Efectividad de omalizumab. 


\section{Introduction}

Chronic rhinosinusitis (CRS) is an inflammation of the nasal cavity and paranasal sinuses characterized by symptoms such as nasal obstruction, rhinorrhea, facial pain, and reduction in or loss of smell lasting for $\geq 12$ weeks, with objective evidence on nasal endoscopy and sinus CT scan. Based on the presence of nasal polyps definied as benign edematous masses in the nasal cavities, CRS is classified as CRS with nasal polyposis $(\mathrm{CRSNP}+)$ and CRS without nasal polyposis (CRSNP-) [1]. Nasal polyposis has a negative impact on quality of life and can lead to considerable workplace absenteeism [2]. The standard treatment of CRSNP+ is medical management with nasal saline irrigations and intranasal corticosteroids for maintenance therapy, systemic corticosteroids and antibiotics for exacerbations, and endoscopic sinus surgery in patients whose medical therapy fails [3].

Asthma is a heterogeneous inflammatory airway disease comprising several phenotypes driven by different pathways [4]. The diagnosis of asthma is based on the presence of intermittent symptoms of wheeze, cough, and chest tightness that may change over time and in intensity with variable expiratory airflow limitation [5]. Inhaled corticosteroids remain the cornerstone of treatment, and current guidelines recommend a step-up approach, with incremental dosing and additonal controller medication in order to achieve symptom control and prevent exacerbations [4-6]. While most patients respond well to these guideline-based treatement approaches, $5 \%-10 \%$ remain refractory despite the maximal therapeutic regimen defining the "severe asthma" population [5,7]. The severe allergic asthma (SAA) phenotype is a type of severe asthma in patients with an allergic background and high serum IgE level. The introduction of anti-IgE antibody treatment (omalizumab) at Step 5 of the Global Initiative for Asthma (GINA) guidelines paved the way for personalized medicine in asthma [4].

A strong association between CRS and asthma has been recognized, with a higher prevalence of CRSNP+ in asthma patients than in the general population ( $7 \%$ vs $4 \%$ ) and the presence of asthma in up to $45 \%$ of patients with CRSNP $+[8,9]$. In addition, approximately $10 \%$ of patients with asthma and CRS report aspirin-exacerbated respiratory disease (AERD) [10]. Many previous studies have provided consistent evidence based on clinical epidemiology, pathophysiology, histology, and treatment outcomes for the CRSNP+ and asthma phenotype, thus sustaining the concept of "one airway disease" $[8,9]$. The clinical phenotype of asthma and associated CRSNP+ is characterized by adult-onset asthma, higher incidence of allergic rhinitis, longer duration of nasal symptoms, increased risk of exacerbation, airway obstruction, uncontrolled and severe asthma, higher CT and endoscopy scores, higher numbers of sinonasal surgical procedures, and poorer quality of life $[8,11]$. Patients with this phenotype may have more intense lower airway inflammation and remodelling associated with the presence of CRSNP+ [12]. Upregulation of the $\mathrm{T}_{\mathrm{H}} 2$ system with predominantly eosinophilic inflammation and elevated serum and nasal levels of IL- 5 and $\operatorname{IgE}$ is found in up to $85 \%$ of cases of CRSNP+ [13]. A recent analysis of inflammatory endotypes in CRS [14] found the cluster associated with high IL-5 levels to be an exclusive phenotype of nasal polyposis, with the highest IgE concentrations and prevalence of asthma. In addition, all samples expressed enterotoxin-specific Staphylococcus aureus IgE. Based on these data, omalizumab, which is currently approved for the management of the SAA, could prove beneficial in the management of CRSNP+ in selected patients [3].

Data on the effectiveness of omalizumab for treatment of SAA in patients with CRSNP+ are currently limited to small series and studies with sometimes contradictory results concerning patient outcomes [15-19]. The aim of this study was to evaluate the effectiveness of omalizumab in real life in patients with SAA and CRSNP+ who tolerated and did not tolerate aspirin.

\section{Methods}

\section{Patients}

This multicenter, noninterventional, retrospective, observational, real-life study was performed in the Department of Pulmonology of the University Hospitals of Besançon, Dijon, Nancy, and Strasbourg and the Regional Hospital of Colmar, France from December 1, 2016 to October 31, 2017. The study was approved by the Institutional Review Board of Société de Pneumologie de Langue Française (French Language Society of Respiratory Medicine) (no. CEPRO 2017-042), and all patients provided their informed consent before their data were retrieved and studied.

Chest physicians with experience in treating severe asthma (based on the European Respiratory Society/American Thoracic Society definition [20]) were asked to provide data on all their patients with SAA and CRSNP+ treated with omalizumab for at least 6 months. To be included, patients had to be adults with uncontrolled SAA despite treatment with Step 4 or 5 of the GINA guidelines [3], for which it was necessary to add omalizumab to improve symptom control and prevent exacerbations. In addition, patients had to have CRSNP+ evaluated by an ear, nose, and throat (ENT) specialist and treated with intranasal corticosteroids. Atopy was proved by skin prick test with common aeroallergens according to European standards [21], and sensitization to at least 1 perennial allergen was confirmed before starting omalizumab. Total serum IgE level was between $120 \mathrm{IU} / \mathrm{mL}$ and $996 \mathrm{IU} / \mathrm{mL}$. The dose (in milligrams) and dosing frequency (every 2 or 4 weeks for 6 months) of omalizumab were based on total serum IgE levels (IU/mL) and body weight (in kilograms), with a maximum dose of $600 \mathrm{mg}$ every 2 weeks. The response to omalizumab at 6 months of treatment was recorded and evaluated by a physician.

\section{Outcome Measures}

The outcome of asthma was assessed based on clinical parameters (dyspnea, cough, number of daytime asthma symptoms/wk, number of nocturnal asthma symptoms/wk, number of salbutamol rescues/wk, number of moderate/severe exacerbations), Asthma Control Test (ACT) score, and lung function variables 6 months before and after treatment with omalizumab. Asthma was considered well controlled with an 
ACT score $\geq 20$, poorly controlled with an ACT score $\leq 19$, and clinically relevant with a change of $\geq 3$ points [10]. A moderatesevere asthma exacerbation was defined as aggravation of respiratory symptoms requiring systemic corticosteroids for at least 3 days and/or hospitalization.

The ENT evaluation included symptoms (pruritus, loss of smell, rhinorrhea, sneezing, nasal obstruction), number of episodes of acute rhinosinusitis, sinus CT images, and endoscopy-based scoring of nasal polyposis 6 months before and after initiation of omalizumab. The severity of the ENT symptoms was evaluated using a visual analog scale (0, not troublesome; and 10, worst possible) [2]. Endoscopy was performed in each nostril separately and graded as follows: 0 , no polyps; 1 , small polyps in the middle meatus not reaching below the inferior border of middle turbinate; 2 , polyps reaching below the lower border of the middle turbinate; 3 , large polyps reaching the lower border of the inferior turbinate or polyps medial to the middle turbinate; 4 , large polyps causing complete obstruction of the inferior nasal cavity [18]. Acute rhinosinusitis was defined as the presence of symptoms/signs such as discolored discharge and purulent secretion in the cavum nasi, severe local pain, and fever $\left(>38^{\circ} \mathrm{C}\right)$ for at least 5 days requiring antibiotics.

The diagnosis of AERD, which was based on clinical history and a positive result in an oral aspirin challenge test performed several years previously, was obtained from the clinical history of the patients at each center. It was impossible to perform the oral aspirin challenge test sooner because of the criteria for uncontrolled asthma [10]. The protocol curently used in the North-East of France inludes incremental doses (30 mg, $60 \mathrm{mg}, 100 \mathrm{mg}, 160 \mathrm{mg}, 325 \mathrm{mg}$ ) every 2 hours, with monitoring in hospital for a few hours up to 1 day, as recommended by current guidelines [10].

The only biological marker in this study was serum eosinophil count, which was measured before and after treatment with omalizumab.

\section{Statistical Analysis}

The statistical analysis was performed using SAS 9.4 (SAS Institute). Qualitative variables are expressed as number or percentage. Quantitative variables are presented as mean (SD). Comparisons of values between baseline and 6 months after treatment with omalizumab were performed using the $t$ test (all patients); comparisons between patients with and without aspirin intolerance were performed using the Fisher exact test. The limit of significance was $P<.05$.

\section{Results}

\section{Patients}

Twenty-four patients were included in the study, 15 who tolerated aspirin and 9 with AERD. Many patients (83\%) had adult-onset asthma. All patients had atopy with symptoms of asthma and rhinitis. The most frequent allergies were to dust mite $(75 \%)$, pet dander (cat, $37.5 \%$; dog, $33.3 \%$ ), grass pollen $(33.3 \%)$, and birch pollen (20.8\%). Some patients had multiple allergies (41.7\%), although all patients were sensitized to at least 1 perennial allergen. Most patients had never smoked
Table 1. Clinical and Demographic Characteristics of the Population at Baseline

\begin{tabular}{|c|c|}
\hline Mean (SD) age, y & $49(16)$ \\
\hline Men/women, $\%$ & $58 / 42$ \\
\hline $\begin{array}{l}\text { Smoking, \% } \\
\text { Never smoker } \\
\text { Ex-smoker } \\
\text { Active smoker }\end{array}$ & $\begin{array}{c}62.50 \\
33.33 \\
4.17\end{array}$ \\
\hline Pack-year mean (SD) & $4.21(7.37)$ \\
\hline $\begin{array}{l}\text { Family history, \% } \\
\text { Atopy } \\
\text { Asthma }\end{array}$ & $\begin{array}{l}12.50 \\
12.50\end{array}$ \\
\hline Asthma diagnosis early/late onset, \% & $17 / 83$ \\
\hline $\begin{array}{l}\text { Allergy, \% } \\
\text { Dust mite } \\
\text { Aspergillus } \\
\text { Alternaria } \\
\text { Cat } \\
\text { Dog } \\
\text { Birch pollen } \\
\text { Ash pollen } \\
\text { Cypress pollen } \\
\text { Grass pollen } \\
\text { Plantain pollen } \\
\text { Mugwort pollen }\end{array}$ & $\begin{array}{c}75 \\
12.50 \\
8.33 \\
37.50 \\
33.33 \\
20.83 \\
12.50 \\
4.17 \\
33.33 \\
12.50 \\
8.33\end{array}$ \\
\hline AERD, \% & 37.50 \\
\hline Previous polyp surgery, $\%$ & 75 \\
\hline $\begin{array}{l}\text { Sinus computed tomography scan, } \% \\
\text { Nasal polyposis } \\
\text { Sinusitis } \\
\text { Nasal polyposis }+ \text { sinusitis }\end{array}$ & $\begin{array}{l}29.17 \\
12.50 \\
58.33\end{array}$ \\
\hline Mean (SD) total serum IgE, IU/mL & $494(337)$ \\
\hline
\end{tabular}

Abbreviation: AERD, aspirin-exacerbated respiratory disease.

$(62.5 \%)$. The baseline characteristics are summarized in Table 1.

\section{Effectiveness of Omalizumab}

Nasal polyposis: Based on total serum IgE levels and body weight, half of the patients received omalizumab every 2 weeks, and the other half every 4 weeks. After 6 months of treatment with omalizumab, ENT symptoms were significantly improved (pruritus, $P=.002$; loss of smell, $P<.001$; rhinorrhea, $P<.001$; sneezing, $P<.001$; nasal obstruction, $P<.001$ ), in parallel with a decrease in the number of episodes of acute rhinosinusitis (4.2 vs $1.3, P<.001$ ).

Three quarters of the patients had undergone surgery for nasal polyposis, which was diagnosed by an ENT specialist during nasal endoscopy at baseline and 6 months after initiating omalizumab. At baseline, $45.8 \%$ of patients had stage 2 nasal polyposis based on endoscopic criteria, $37.5 \%$ had stage 3 disease, and $16.7 \%$ had stage 1 disease. The stage of nasal polyposis improved after 6 months in several patients (Table 2), although the difference was not statistically significant.

At baseline, the sinus CT scan showed images of sinusitis with nasal polyposis in $58.3 \%$ of patients, only nasal polyposis in $29.2 \%$ of patients, and sinusitis without nasal polyposis in 
Table 2. Clinical, Respiratory, Biological, and Imaging Parameters Before and After 6 Months of Treatment With Omalizumab

\begin{tabular}{|c|c|c|c|}
\hline Parameter & Before & After & $P$ Value \\
\hline \multicolumn{4}{|l|}{ Mean (SD) ENT severity, VAS symptom score } \\
\hline Pruritus & $1.88(2.85)$ & 0 & .002 \\
\hline Loss of smell & $8.50(1.58)$ & $5.08(3.42)$ & $<.001$ \\
\hline Rhinorrhea & $8.00(2.57)$ & $4.83(3.27)$ & $<.001$ \\
\hline Sneezing & $8.00(2.57)$ & $0.42(1.38)$ & $<.001$ \\
\hline Nasal obstruction & $7.38(3.97)$ & $1.17(3.39)$ & $<.001$ \\
\hline Mean (SD) number of episodes of acute rhinosinusitis & $4.21(1.28)$ & $1.29(1.49)$ & $<.001$ \\
\hline \multicolumn{3}{|l|}{ Endoscopic nasal polyp score, No. \% } & .415 \\
\hline 1 & 16.67 & 20.83 & \\
\hline 2 & 45.83 & 58.33 & \\
\hline 3 & 37.50 & 20.83 & \\
\hline \multicolumn{3}{|l|}{ Sinus computed tomography scan, $\%$} & .006 \\
\hline Nasal polyps & 29.17 & 70.83 & \\
\hline Sinusitis & 12.50 & 4.17 & \\
\hline Nasal polyps + sinusitis & 58.33 & 25.00 & \\
\hline \multicolumn{4}{|l|}{ Respiratory symptoms } \\
\hline \multicolumn{3}{|l|}{ Dyspnea (mMRC) score, No. (\%) } & $<.001$ \\
\hline 0 & 0 & 25.00 & \\
\hline 1 & 20.83 & 41.67 & \\
\hline 2 & 12.50 & 29.16 & \\
\hline 3 & 62.50 & 4.17 & \\
\hline 4 & 4.17 & 0 & \\
\hline Cough, No. $(\%)$ & 83.33 & 62.50 & .028 \\
\hline Mean (SD) number of daytime asthma symptoms/wk & $5.25(2.95)$ & $1.67(1.28)$ & $<.001$ \\
\hline Mean (SD) number of nocturnal asthma symptoms/wk & $2.88(2.09)$ & $0.54(0.96)$ & $<.001$ \\
\hline Mean (SD) number of salbutamol rescues/wk & $13.29(7.51)$ & $3.63(3.08)$ & $<.001$ \\
\hline Mean (SD) ACT score & $12.21(4.09)$ & $19.46(3.34)$ & $<.001$ \\
\hline Mean (SD) number of asthma exacerbations & $4.58(1.25)$ & $1.42(1.44)$ & $<.001$ \\
\hline \multicolumn{4}{|l|}{ Mean (SD) lung function } \\
\hline $\mathrm{FEV}_{1}, \%$ & $60.08(18.24)$ & $72.88(19.43)$ & $<.001$ \\
\hline $\mathrm{FVC}, \%$ & $83.17(17.88)$ & $93.38(17.06)$ & $<.001$ \\
\hline $\mathrm{FEV}_{1} / \mathrm{FVC}, \%$ & $61.50(13.96)$ & $66.67(11.21)$ & .017 \\
\hline Mean (SD) blood eosinophil count, G/L & $0.91(0.51)$ & $0.52(0.38)$ & .006 \\
\hline
\end{tabular}

Abbreviations: ACT, Asthma Control Score; ENT, ear, nose, and throat; FEV 1 , forced expiratory volume in the first second; FVC, forced vital capacity; mMRC, modified Medical Research Council; VAS, visual analog scale.

$12.5 \%$ of patients. Omalizumab significantly improved the CT scan opacities indicative of sinusitis, thus making the images of nasal polyposis more visible (Table 2). The improvement in the scan image at 6 months was evident in $37.5 \%$ of patients.

Asthma: Omalizumab significantly improved respiratory symptoms (dyspnea, $P<.001$; and cough, $P=.028$ ) and decreased the number of asthma daytime and nocturnal symptoms per week, thus reducing the need for rescue medication $(P<.001)$. The change in the mean ACT score was significant, increasing from 12.2 to $19.5(P<.001)$. Omalizumab significantly reduced the number of asthma exacerbations at 6 months (4.6 vs 1.4, $P<.001)$

Lung function was significantly improved by treatment, with an increase of $12.8 \%$ in $\mathrm{FEV}_{1}(P<.001)$, an increase of $10.2 \%$ in FVC $(P<.001)$, and a decrease in bronchial obstruction $\left(\mathrm{FEV}_{1} / \mathrm{FVC} 61.5 \%\right.$ before treatment vs $66.7 \%$ after, $P=.017)$.

Omalizumab significantly decreased the blood eosinophil level $(0.91 \mathrm{G} / \mathrm{L}$ at baseline vs $0.52 \mathrm{G} / \mathrm{L}$ at 6 months, $P=.006)$.
The clinical, lung function, biological, and imaging characteristics before and after the treatment are summarized in Table 2 .

AERD: There were no differences in clinical, respiratory functional, biological, and imaging parameters at baseline in patients with and without AERD (Table 3 ). The comparative analysis of the same parameters after 6 months of treatment with omalizumab in patients with and without AERD progressed similarly in terms of clinical, respiratory, and biological outcomes. The only significant difference between the groups was a more marked improvement in sinus opacities indicative of sinusitis in patients with AERD than in patients without AERD (Table 4).

\section{Discussion}

Our real-life study showed that omalizumab was an effective therapy in patients with SAA and CRSNP+ and that 
Table 3. Clinical, Respiratory, Biological, and Imaging Parameters at Baseline in Patients With and Without AERD

\begin{tabular}{|c|c|c|c|}
\hline Parameter & Without AERD $(n=15)$ & With AERD (n=9) & $P$ Value \\
\hline \multicolumn{4}{|l|}{ ENT severity, mean (SD) VAS symptom score } \\
\hline Pruritus & $2.00(2.40)$ & $1.67(2.59)$ & .809 \\
\hline Loss of smell & $8.40(1.44)$ & $8.67(1.33)$ & .701 \\
\hline Rhinorrhea & $7.60(1.87)$ & $8.67(1.63)$ & .309 \\
\hline Sneezing & $3.00(2.80)$ & $2.67(2.96)$ & .821 \\
\hline Nasal obstruction & $7.53(3.29)$ & $7.11(3.41)$ & .813 \\
\hline Mean (SD) number of episodes of acute rhinosinusitis & $4.53(1.10)$ & $3.67(1.63)$ & .276 \\
\hline \multicolumn{3}{|l|}{ Endoscopic nasal polyp score, $\%$} & .519 \\
\hline 1 & 20.00 & 33.33 & \\
\hline 2 & 46.67 & 33.33 & \\
\hline 3 & 33.33 & 33.33 & \\
\hline \multicolumn{3}{|l|}{ Sinus CT scan, $\%$} & .278 \\
\hline Nasal polyps & 33.33 & 22.22 & \\
\hline Sinusitis & 20.00 & 0 & \\
\hline Nasal polyps + sinusitis & 46.67 & 77.78 & \\
\hline \multicolumn{4}{|l|}{ Respiratory symptoms } \\
\hline Dyspnea (mMRC) score, No. (\%) & & & .837 \\
\hline 1 & 13.33 & 33.33 & \\
\hline 2 & 20.00 & 0 & \\
\hline 3 & 66.67 & 55.56 & \\
\hline 4 & 0 & 11.11 & \\
\hline Cough, No. (\%) & 93.33 & 66.67 & .167 \\
\hline Mean (SD) number of daytime asthma symptoms/wk & $5.47(2.49)$ & $4.89(2.09)$ & .660 \\
\hline Mean (SD) number of nocturnal asthma symptom/wk & $2.93(1.78)$ & $2.78(1.48)$ & .863 \\
\hline Mean (SD) number of salbutamol rescues/wk & $15.13(7.08)$ & $10.22(4.02)$ & .100 \\
\hline Mean (SD) ACT score & $12.00(3.33)$ & $12.56(3.48)$ & .759 \\
\hline Mean (SD) number of asthma exacerbations & $4.53(1.10)$ & $4.47(1.26)$ & .818 \\
\hline \multicolumn{4}{|l|}{ Mean (SD) values for lung function } \\
\hline $\mathrm{FEV}_{1}, \%$ & $63.67(17.33)$ & $54.11(10.57)$ & .182 \\
\hline $\mathrm{FVC}, \%$ & $84.13(18.56)$ & $81.56(5.60)$ & .691 \\
\hline $\mathrm{FEV}_{1} / \mathrm{FVC}, \%$ & $63.40(10.43)$ & $58.33(13.63)$ & .445 \\
\hline Mean (SD) blood eosinophil count, G/L & $0.81(0.29)$ & $1.07(0.47)$ & .312 \\
\hline Mean total serum IgE, IU/mL & $517(320)$ & $455(284)$ & 679 \\
\hline
\end{tabular}

Abbreviations: ACT, Asthma Control Score; AERD, aspirin-exacerbated respiratory disease; ENT, ear, nose, and throat; FEV ${ }_{1}$, forced expiratory volume in the first second; FVC, forced vital capacity; mMRC, modified Medical Research Council; VAS, visual analog scale.

it led to improvement of asthma (symptoms, control, lung function, rescue medication for attacks, and exacerbation), and ENT outcomes (symptoms, CT scan images, number of episodes of acute rhinosinusitis) independently of the presence of AERD. The study population is characteristic of the asthma-CRSNP+ phenotype, with predominant adult-onset asthma, a high prevalence of allergic rhinitis and previous sinonasal surgery, a high exacerbation rate, poorly controlled asthma, airway obstruction, and an eosinophilic inflammatory pattern $[7,8,12,22]$.

The prevalence of AERD in this study was $37.5 \%$, which was higher than previously reported for severe asthma $(14.9 \%)$ [10]. One possible explaination for this difference is the general underestimation of AERD. Furthermore, prevalence increases to $21 \%$ in severe asthma when the asprin challenge test is performed systematically [10]. Similarly, the prevalence of AERD in patients with CRSNP+ is estimated at $8.7 \%$, while up to $70 \%$ of patients report sensitivity to red wine and other alcoholic beverages, thus indicating a diagnosis of
AERD, albeit one that has not been confirmed with a challenge test [23]. Large-scale studies on the association between asthma and CRSNP+ are needed to determine the real prevalence of AERD based on an aspirin challenge test when the clinical history is compatible with the diagnosis.

The present study confirmed the benefit of omalizumab for relief of the symptoms of persistent allergic rhinitis (pruritus, loss of smell, rhinorrhea, sneezing, nasal obstruction) in SAA patients, as previously reported [24]. In a recent meta-analysis including 2870 patients with allergic rhinitis [25], omalizumab reduced both daily nasal symptoms and use of nasal rescue medication. These results are not surprising, given that allergic asthma and allergic rhinitis share pathogenic mechanisms and common triggers and are considered to be components of a single IgE-mediated inflammatory condition. The allergic profile identified in this study is typical for the northeastern region of France.

While data on omalizumab and allergic airway disease are abundant, data on CRSNP+ in the literature are limited 
Table 4. Clinical, Respiratory, Biological, and Imaging Parameters After 6 Months of Treatment by Omalizumab in Patients With and Without AERD

\begin{tabular}{|c|c|c|c|}
\hline Parameter & Without AERD $(\mathrm{n}=15)$ & With AERD $(n=9)$ & $P$ Value \\
\hline \multicolumn{4}{|l|}{ ENT severity, Mean (SD) VAS symptom score } \\
\hline Pruritus & 0 & 0 & \\
\hline Loss of smell & $4.87(2.59)$ & $5.44(2.62)$ & .703 \\
\hline Rhinorrhea & $4.87(2.59)$ & $4.78(2.12)$ & .950 \\
\hline Sneezing & $0.33(0.62)$ & $0.56(0.98)$ & .736 \\
\hline Nasal obstruction & $4.20(2.83)$ & $4.11(2.74)$ & .952 \\
\hline Mean (SD) number of acute rhinosinusitis episodes & $1.47(1.29)$ & $1.00(1.11)$ & .454 \\
\hline \multicolumn{3}{|l|}{ Endoscopic nasal polyp score, $\%$} & 1.000 \\
\hline 1 & 13.33 & 33.33 & \\
\hline 2 & 73.33 & 33.33 & \\
\hline 3 & 13.33 & 33.33 & \\
\hline \multicolumn{3}{|l|}{ Sinus CT scan, \% } & .004 \\
\hline Nasal polyps & 53.33 & 100.00 & \\
\hline Sinusitis & 6.670 & & \\
\hline Nasal polyps + sinusitis & 40.00 & 0 & \\
\hline \multicolumn{4}{|l|}{ Respiratory symptom } \\
\hline Dyspnea (mMRC) score, No. (\%) & & & .370 \\
\hline 0 & 33.33 & 11.11 & \\
\hline 1 & 33.33 & 0 & \\
\hline 2 & 33.33 & 55.56 & \\
\hline 3 & 0 & 33.33 & \\
\hline Cough, No. (\%) & 73.33 & 44.44 & .192 \\
\hline Mean (SD) number of daytime asthma symptoms/wk & $1.73(1.12)$ & $1.56(0.94)$ & .748 \\
\hline Mean (SD) number of nocturnal asthma symptom/wk & $0.33(0.53)$ & $0.89(0.99)$ & .255 \\
\hline Mean (SD) number of salbutamol rescue/wk & $3.87(2.29)$ & $3.22(2.47)$ & .659 \\
\hline Mean ACT score & $18.80(2.85)$ & $20.56(2.39)$ & .195 \\
\hline Mean (SD) number of asthma exacerbations & $1.47(1.29)$ & $1.33(1.04)$ & .823 \\
\hline \multicolumn{4}{|l|}{ Mean (SD) values for lung function } \\
\hline $\mathrm{FEV}_{1}, \%$ & $76.00(20.53)$ & $67.67(7.78)$ & .258 \\
\hline FVC, $\%$ & $94.60(17.17)$ & $91.33(8.00)$ & .609 \\
\hline $\mathrm{FEV}_{1} / \mathrm{FVC}, \%$ & $68.53(8.03)$ & $63.56(9.73)$ & .313 \\
\hline Mean (SD) blood eosinophil count, G/L & $0.51(0.25)$ & $0.54(0.39)$ & .881 \\
\hline
\end{tabular}

Abbreviations: ACT, Asthma Control Score; AERD, aspirin-exacerbated respiratory disease; ENT, ear, nose, and throat; FEV ${ }_{1}$, forced expiratory volume in the first second; FVC, forced vital capacity; mMRC, modified Medical Research Council; VAS, visual analog scale

to a few small studies with a short treatment period (usually 16 weeks) $[3,26]$. Three-quarters of the study population had previously undergone surgery for nasal polyposis. In several cases of recalcitrant CRSNP+ with severe ENT symptoms and multiple surgical interventions, additional adjuvant medical therapies such as leukotriene antagonists, low-dose macrolides, topical antibiotics, and oral antifungal and biologic agents could prove beneficial [3].

In this study, omalizumab was effective against ENT symptoms secondary to CRSNP+ (loss of smell, rhinorrhea, nasal obstruction) and asthma symptoms (dyspnea, cough, number of daytime asthma symptoms/wk, number of nocturnal asthma symptom/wk), in line with other published data $[15,18]$. A previous study including patients with nasal polyposis and asthma treated with omalizumab for 16 weeks [18] showed a significant improvement in several symptoms, such as nasal congestion, rhinorrhea, loss of smell, dyspnea, and wheeze, with no benefit for cough. Decreased cough in patients with SAA and CRSNP+ who have taken omalizumab for 6 months is an original finding of our study.
Similarly, consistent with data from a real-life study by Bidder et al [17], we observed a significant improvement in asthma control (ACT score) at 6 months of treatment in patients with SAA and CRSNP+. The authors demonstrated a significant improvement in sinonasal outcomes (SNOT-22) and asthma control (Asthma Control Questionnaire [ACQ] 7) after 16 weeks of treatment with omalizumab in a similar population. Other previous studies including patients with SAA reported the benefit of omalizumab for disease control, with an improvement in the ACQ or ACT score [27,28], although data on the impact of this treatment in patients with SAA and CRSNP+ are currently very limited.

Other original results of this study are the significant decrease in the number of acute rhinosinusitis and asthma exacerbations requiring medical treatment and rescue ß-agonists 6 months after initiation of omalizumab. To the best of our knowledge, this is the first study in the literature to report this finding in patients with SAA and CRSNP+. The positive impact of omalizumab on the outcome of SAA has been demonstrated elsewhere [29,30]. A systematic 
review including 24 real-life studies on the effectiveness of omalizumab in SAA [29] confirmed the short- and long-term benefit of anti-IgE therapy in terms of the following: asthma control; relief of symptoms; severe exacerbations; associated work/school days lost; use of healthcare resources, in particular hospitalization; hospital length of stay; specialist or emergency department visits; reduction in or discontinuation of other asthma medications; lung function; and quality of life.

In the present study, $\mathrm{FEV}_{1}$ was significantly increased $(>10 \%)$ at 6 months of treatment compared with baseline; this finding is consistent with the data reported by Mansur et al [27] in patients with SAA without CRSNP+ [27]. The improvement in lung function parameters after treatment with omalizumab was previously reported in SAA patients, independently of the presence of CRSNP+ $[27,30]$. However, our study is the first to report this effect in patients with SAA and CRSNP+.

The impact of omalizumab on endoscopic scoring of nasal polyposis is controversial. Consistent with Pinto et al [31] and in contrast with other authors $[15,18]$, the present study did not show any significant change in the endoscopic polyp score after 6 months of treatment with omalizumab. Two possible explanations for this observation are first, that all published data are the results of series or small cohorts and "big" data are lacking, and second, our study is a retrospective multicenter study in which endoscopy was not performed by the same ENT specialist.

The present study confirms the improvement in CT sinus scan opacities in patients treated with omalizumab, as previously described [15,18,31]. Interestingly, in the study by Gevaert et al [18], omalizumab significantly improved the Lund-Mackay score only in patients with allergic asthma and CRSNP+ (in contrast to those with nonallergic asthma). All the patients included in our study were allergic, although the Lund-Mackay score was not available in all cases.

To the best of our knowledge, this is the first study to show a significant decrease in blood eosinophil count in SAA patients with CRSNP+ treated with omalizumab. Eosinophil counts before treatment were higher $(0.91 \mathrm{G} / \mathrm{L})$ than in the study by Gevaert et al [18] (0.39 G/L). One possible explanation for this observation could be that in our study, all patients were allergic, while in the other study, the population was mixed: 7 patients were allergic and 8 nonallergic. High blood eosinophil counts $(>0.3 \mathrm{G} / \mathrm{L})$ in asthmatic patients are associated with diminished lung function, more frequent exacerbations, and poorer asthma control [32], and omalizumab decreases the blood eosinophil count in treated patients with SAA [33], as also found in our study. Recent data $[28,34]$ showed that omalizumab is equally effective in patients with high counts $(\geq 0.3 \mathrm{G} / \mathrm{L})$ and low counts $(<0.3 \mathrm{G} / \mathrm{L})$, with a significant improvement in asthma control and a reduction in the annual exacerbation/hospitalization rate.

The present study confirms previous data, which show similar effectiveness of omalizumab for patients with and without AERD [18]. The mechanisms which could explain the benefit of omalizumab in AERD are not fully understood. One of the pathogenic mechanisms recognized in AERD is the activation of mast cells via cysteinyl leukotriene-driven IL-33 [10]. A recent study showed that omalizumab reduces overproduction of cysteinyl leukotriene [35] probably by decreasing the activation of mast cells on the IL-33 pathway involved in persistent type 2 inflammation in patients with AERD.

Our results are in line with data from a Japanese cohort including 21 patients with AERD treated with omalizumab. A significant improvement was observed in all asthma and ENT symptoms, with a decrease in the frequency of asthma exacerbations and in the blood eosinophil count [35]. On the other hand, this study failed to show a significant improvement in lung function, as was the case in the present study. In addition, our study showed that omalizumab significantly improved CT scan images of sinusitis in patients with AERD compared with patients without AERD. Ours is the first report of this finding. In a case series of patients with AERD, 6 months of therapy with omalizumab significantly decreased the number of exacerbations and improved patients' quality of life. In addition, patients developed tolerance to nonsteroidal anti-inflammatory drugs [36]. Another recent study confirmed that administration of omalizumab in atopic patients with AERD, even for 16 weeks, improved clinical tolerability to desensitization to aspirin [37]. Omalizumab seems to be an interesting therapeutic approach for patients with AERD.

A recent study [17] showed the effectiveness of omalizumab (16 weeks) compared with surgery in patients with CRSNP+ and SAA, with a parallel improvement in sinonasal outcomes and asthma control in both groups, thus supporting the "one airway disease" hypothesis. Recent progress in this domain indicates that "one airway disease" may soon be treated with a single biologic agent (anti-IgE, anti-IL5, or anti-IL4/13) $[3,26]$.

Ours is the largest real-life study to date to analyze the effectiveness of omalizumab in patients with SAA and CRSNP+. Omalizumab improved asthma outcomes (symptoms, control, lung function, asthma attacks and exacerbations, use of rescue medication), ENT symptoms, CT scan images, the number of episodes of acute rhinosinusitis, and blood eosinophil count, with no significant effect on the nasal polyposis score.

Outcomes were similar in patients with AERD and patients without AERD, except for the improvement in sinusitis on sinus CT scans after 6 months of treatment with omalizumab, which was more evident in the first group. These results need to be verified by prospective studies including large cohorts of patients. Biologic therapy could be an alternative in the treatment of recalcitrant CRSNP+ in SAA patients with or without AERD.

\section{Funding}

The authors declare that no funding was received for the present study.

\section{Conflicts of Interest}

A Tiotiu has participated on scientific advisory boards for Menarini and Novartis Pharma and has been a coinvestigator in studies for AstraZeneca, Novartis Pharma, and Sanofi.

JP Oster has participated on scientific advisory boards for Novartis Pharma.

P Roux has participated on scientific advisory boards for Novartis Pharma. 
G Peiffert has participated on scientific advisory boards for Chiesi and Novartis Pharma.

P Bonniaud has participated on scientific advisory boards for Novartis Pharma and has been a coinvestigator in studies for AstraZeneca, GSK, Novartis Pharma, and Sanofi.

JC Dalphin has participated on scientific advisory boards for Novartis Pharma and Teva.

F de Blay has participated on scientific advisory boards for ALK, AstraZeneca, GSK, Novartis Pharma, and Teva and has been a coinvestigator in studies for ALK, AstraZeneca, GSK, Novartis Pharma, and Sanofi.

PL Nguyen declares no conflicts of interest.

\section{References}

1. Wu D, Bleier BS, Li L, Zhan X, Zhang L, Lv Q, et al. Clinical Phenotypes of Nasal Polyps and Comorbid Asthma Based on Cluster Analysis of Disease History. J Allergy Clin Immunol Pract. 2018;6:1297-305.

2. Bachert C, Sousa AR, Lund VJ, Scadding GK, Gevaert P, Nasser $S$, et al. Reduced need for surgery in severe nasal polyposis with mepolizumab: Randomized trial. J Allergy Clin Immunol. 2017; 140:1024-31.

3. Rivero A, Liang J. Anti-IgE and Anti-IL5 Biologic Therapy in the Treatment of Nasal Polyposis: A Systematic Review and Metaanalysis. Ann Otol Rhinol Laryngol. 2017;126:739-47.

4. Chung KF. Precision medicine in asthma: linking phenotypes to targeted treatments. Curr Opin Pulm Med. 2018;24:4-10.

5. ( $\left.{ }^{*} N E W\right) 2018$ GINA Report: Global Strategy for Asthma Management and Prevention. Available from: https:// ginasthma.org/2018-gina-report-global-strategy-for-asthmamanagement-and-prevention

6. Valero A, Olaguibel J, Delgado J, Plaza V, Álvarez F, Molina J, et al. Re-evolution of asthma management: dilemmas and new paradigms. J Investig Allergol Clin Immunol. 2018 Nov 9;0. doi: 10.18176/jiaci.0345

7. Opina MTD, Moore WC. Phenotype-Driven Therapeutics in Severe Asthma. Curr Allergy Asthma Rep. 2017;17:10. doi: 10.1007/s11882-017-0678-1

8. Tiotiu A, Plavec D, Novakova S, Mihaicuta S, Novakova P, Labor $M$, et al. Current opinions for the management of asthma associated with ear, nose and throat comorbidities. Eur Respir Rev. 2018 Nov 21;27. doi: 10.1183/16000617.0056-2018

9. Langdon C, Mullol J. Nasal polyps in patients with asthma: prevalence, impact, and management challenges. J Asthma Allergy. 2016;9:45-53.

10. Kowalski ML, Agache I, Bavbek S, Bakirtas A, Blanca M, Bochenek $G$, et al. Diagnosis and management of NSAIDExacerbated Respiratory Disease (N-ERD)-a EAACI position paper. Allergy. 2019;74:28-39.

11. Westerhof GA, Coumou H, de Nijs SB, Weersink EJ, Bel EH. Clinical predictors of remission and persistence of adult-onset asthma. J Allergy Clin Immunol. 2018;141:104-9.

12. Porsbjerg C, Menzies-Gow A. Co-morbidities in severe asthma: Clinical impact and management. Respirology. 2017;22:651-61.

13. Gurrola J, Borish L. Chronic rhinosinusitis: Endotypes, biomarkers, and treatment response. J Allergy Clin Immunol. 2017;140:1499-508
14. Tomassen P, Vandeplas G, Van Zele T, Cardell L-O, Arebro J, Olze $\mathrm{H}$, et al. Inflammatory endotypes of chronic rhinosinusitis based on cluster analysis of biomarkers. J Allergy Clin Immunol. 2016;137:1449-56.

15. Tajiri T, Matsumoto $H$, Hiraumi $H$, Ikeda $H$, Morita $K$, Izuhara $\mathrm{K}$, et al. Efficacy of omalizumab in eosinophilic chronic rhinosinusitis patients with asthma. Ann Allergy Asthma Immunol. 2013;110:387-8.

16. Vennera M del C, Picado C, Mullol J, Alobid I, Bernal-Sprekelsen M. Efficacy of omalizumab in the treatment of nasal polyps. Thorax. 2011;66:824-5.

17. Bidder T, Sahota J, Rennie C, Lund VJ, Robinson DS, Kariyawasam HH. Omalizumab treats chronic rhinosinusitis with nasal polyps and asthma together-a real life study. Rhinology. 2018;56:42-5.

18. Gevaert P, Calus L, Van Zele T, Blomme K, De Ruyck N, Bauters $W$, et al. Omalizumab is effective in allergic and nonallergic patients with nasal polyps and asthma. J Allergy Clin Immunol. 2013;131:110-6.

19. Penn R, Mikula S. The role of anti-IgE immunoglobulin therapy in nasal polyposis: a pilot study. Am J Rhinol. 2007;21:42832.

20. Chung KF, Wenzel SE, Brozek JL, Bush A, Castro M, Sterk PJ, et al. International ERS/ATS guidelines on definition, evaluation and treatment of severe asthma. Eur Respir J. 2014;43:34373.

21. Heinzerling L, Mari A, Bergmann K-C, Bresciani M, Burbach G, Darsow $U$, et al. The skin prick test - European standards. Clin Transl Allergy. 2013;3:3.doi: 10.1186/2045-7022-3-3.

22. de Groot JC, Storm $H$, Amelink M, de Nijs SB, Eichhorn $E_{\text {, }}$ Reitsma $\mathrm{BH}$, et al. Clinical profile of patients with adult-onset eosinophilic asthma. ERJ Open Res. 2016;2. pii: 00100-2015

23. Kennedy JL, StonerAN, Borish L.Aspirin-exacerbated respiratory disease: Prevalence, diagnosis, treatment, and considerations for the future. Am J Rhinol Allergy. 2016;30:407-13.

24. Masieri S, Cavaliere C, Begvarfaj E, Rosati D, Minni A. Effects of omalizumab therapy on allergic rhinitis: a pilot study. Eur Rev Med Pharmacol Sci. 2016;20:5249-55.

25. Tsabouri S, Tseretopoulou X, Priftis K, Ntzani EE. Omalizumab for the treatment of inadequately controlled allergic rhinitis: a systematic review and meta-analysis of randomized clinical trials. J Allergy Clin Immunol Pract. 2014;2:332-40.

26. Tsetsos N, Goudakos JK, Daskalakis D, Konstantinidis I, Markou K. Monoclonal antibodies for the treatment of chronic rhinosinusitis with nasal polyposis: a systematic review. Rhinology. 2018;56:11-21.

27. Mansur AH, Srivastava S, Mitchell V, Sullivan J, Kasujee I. Longterm clinical outcomes of omalizumab therapy in severe allergic asthma: Study of efficacy and safety. Respir Med. 2017;124:36-43.

28. Casale TB, Luskin AT, Busse W, Zeiger RS, Trzaskoma B, Yang $M$, et al. Omalizumab Effectiveness by Biomarker Status in Patients with Asthma: Evidence From PROSPERO, A Prospective Real-World Study. J Allergy Clin Immunol Pract. 2019;7:156-64

29. Abraham I, Alhossan A, Lee CS, Kutbi H, MacDonald K. 'Reallife' effectiveness studies of omalizumab in adult patients with severe allergic asthma: systematic review. Allergy. 2016;71:593-610 
30. Alhossan A, Lee CS, MacDonald K, Abraham I. 'Real-life' Effectiveness Studies of Omalizumab in Adult Patients with Severe Allergic Asthma: Meta-analysis. J Allergy Clin Immunol Pract. 2017;5:1362-70.

31. Pinto JM, Mehta N, DiTineo M, Wang J, Baroody FM, Naclerio RM. A randomized, double-blind, placebo-controlled trial of anti-lgE for chronic rhinosinusitis. Rhinology. 2010;48:31824.

32. Pretolani M, Soussan D, Poirier I, Thabut G, Aubier M, COBRA Study Group, et al. Clinical and biological characteristics of the French COBRA cohort of adult subjects with asthma. Eur Respir J. 2017;50(2). doi: 10.1183/13993003.000192017

33. Pelaia C, Calabrese $C$, Barbuto $S$, Busceti MT, Preianò $M$, Gallelli $\mathrm{L}$, et al. Omalizumab lowers asthma exacerbations, oral corticosteroid intake and blood eosinophils: Results of a 5-YEAR single-centre observational study. Pulm Pharmacol Ther. 2019;54:25-30

34. Humbert M, Taillé C, Mala L, Le Gros V, Just J, Molimard M, et al. Omalizumab effectiveness in patients with severe allergic asthma according to blood eosinophil count: the STELLAIR study. Eur Respir J. 2018;51. doi: 10.1183/13993003.025232017

35. Hayashi H, Mitsui C, Nakatani E, Fukutomi Y, Kajiwara K, Watai $K$, et al. Omalizumab reduces cysteinyl leukotriene and $9 \alpha, 11 \beta$-prostaglandin F2 overproduction in aspirinexacerbated respiratory disease. J Allergy Clin Immunol. 2016;137:1585-7.

36. Phillips-Angles $E_{1}$ Barranco $P$, Lluch-Bernal $M$, DominguezOrtega J, López-Carrasco V, Quirce S. Aspirin tolerance in patients with nonsteroidal anti-inflammatory drugexacerbated respiratory disease following treatment with omalizumab. J Allergy Clin Immunol Pract. 2017;5:842-5.

37. Lang DM, Aronica MA, Maierson ES, Wang X-F, Vasas DC, Hazen SL. Omalizumab can inhibit respiratory reaction during aspirin desensitization. Ann Allergy Asthma Immunol. 2018;121:98-104.

\section{Manuscript received December 10, 2018; accepted for publication March 22, 2019.}

\section{- Angelica Tiotiu}

Department of Pulmonology
University Hospital of Nancy
9 Rue du Morvan
54500 Vandoeuvre-les-Nancy, France
E-mail: angelica.tiotiu@yahoo.com 